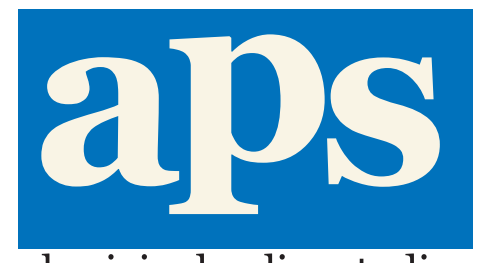

aboriginal policy studies

\title{
Article
}

\section{Emerging Themes in Academic Research in Urban Aboriginal Identities in Canada, 1996-2010}

\author{
Evelyn J. Peters \\ aboriginal policy studies, Vol. 1, no. 1, 2011, pp. 78-105
}

This article can be found at:

http://ejournals.library.ualberta.ca/index.php/aps/1/1/Peters.pdf

ISSN: 1923-3299

aboriginal policy studies is an online, peer-reviewed and multidisciplinary journal that publishes original, scholarly, and policy-relevant research on issues relevant to Métis, non-status Indians and urban Aboriginal people in Canada. For more information, please contact us at apsjournal@ualberta.ca or visit our website at

www.ualberta.ca/NATIVESTUDIES/aps/

or

http://ejournals.library.ualberta.ca/index.php/aps/ 


\title{
Emerging Themes in Academic Research in Urban Aboriginal Identities in Canada, 1996-2010
}

\author{
Evelyn J. Peters \\ University of Winnipeg
}

\begin{abstract}
This paper reviews academic work on urban Aboriginal identities in Canada since the publication of the report of the Royal Commission on Aboriginal Peoples in 1993. In contrast to earlier work, there is now a substantial body of literature addressing a variety of issues on the report from many disciplinary perspectives. There have also been some major shifts in areas of emphasis, and there is, increasingly, material being produced that examines the mechanisms through which cities are defined so that Aboriginal cultures and identities are viewed as being out of place. In contrast to earlier perspectives, there are strong arguments that success in the urban milieu is not incompatible with the retention or emergence of positive Aboriginal identities and communities.
\end{abstract}

\section{Emerging Themes in Academic Research in Urban Aboriginal Identities in Canada, 1996-2010}

In a 1996 paper, I reviewed existing work both in published academic work and in the grey literature of a variety of government and other unpublished studies, and examined the changing discourses in them on urban Aboriginal ${ }^{1}$ people (Peters 1996). I argued that early conclusions, beginning around the 1940s and 1950s and coinciding with increased Aboriginal migration to cities, were that successful adaptation to urban life was incompatible with Aboriginal cultures and identities. Aboriginal migration to urban areas was viewed as a decision to abandon Aboriginal identities and communities and assimilate into the mainstream. Return migration to reserves and

aboriginal policy studies, Vol. 1, no. 1, 2011

ISSN: 1923-3299

www.ualberta.ca/NATIVESTUDIES/aps/ 
rural communities, seen as islands of traditional Aboriginal cultures, was interpreted as a failure to adapt to urban life. The literature began to show a shift in attitudes about urban Aboriginal people around the mid-1980s, and urban Aboriginal people began to be seen, not through the lenses of culture, but almost exclusively through lenses of poverty and dysfunction.

In the 1990s, the Royal Commission on Aboriginal Peoples was very influential in refocusing perspectives about urban Aboriginal cultures and identities. The Commission reported from the public hearings it conducted across the country that,

Crossing the city limits does not transform Aboriginal people into non-Aboriginal people; they go on being the particular kind of person they have always been-Cree, Dene, Mohawk, Haida. The intention of Aboriginal people to go on expressing their Aboriginal identity and to pass it on to their children was a consistent theme in presentations by urban Aboriginal people at the round table and in hearings across the country $(1993,3)$.

In its final report, the Commission argued that strong cultural identities were an important element of Aboriginal people's success in cities (Royal Commission on Aboriginal Peoples 1996). Despite these assertions, a number of authors have detected some internal contradictions in the Commission's report, arguing that the Commission presented cities as places of cultural loss and associated cultural vitality with reserves and rural Métis and Inuit communities (Andersen and Denis 2003; Cairns 2000; Newhouse and Peters 2003).

The post-1996 literature demonstrates some distinct departures from earlier work, echoing the arguments presenters put forward in the public hearings for the Royal Commission on Aboriginal peoples. According to Warry $(2007,111)$ for example, "[p]erhaps the greatest myth about Aboriginal people is that when they move to the city, they abandon their culture." In his learning circles with seven urban Aboriginal men in Toronto in 2003 , Restoule $(2005,13)$ found that, despite the different histories of his participants, "all of the participants are oriented very strongly toward maintaining their Aboriginal cultural identity. Living in urban areas does not necessitate giving up Aboriginal identity." The Urban Aboriginal Task Force (2007), a community-based study of over 1700 urban Aboriginal people in Thunder Bay, Ottawa, Barrie-Midland-Orillia, Sudbury, and Kenora, found 
that most (73\%) stressed the importance of traditional Aboriginal cultures and 80 percent participated in Aboriginal cultural activities. Aboriginal institutions have been key in supporting positive urban Aboriginal identities. Janovich's $(2003,549)$ work for example, on Native women's creation of a second stage shelter for Aboriginal women in Thunder Bay in the 1970s, argued that by taking control of services and using them to protect Aboriginal identity in the city, these women "engendered a conception of Aboriginal identity that opposed the view that it could not exist off-reserve." Other researchers reported similar roles for urban Aboriginal organizations (Newhouse 2003; Proulx 2003; Silver 2006).

Understanding urban Aboriginal identities is important to public policy in Canada. As recent census results show, increasingly the Canadian Aboriginal population is an urban one. While there is a growing amount of material available about Aboriginal experiences and histories generally, there is very little public knowledge about how Aboriginal people define their cultural identities in cities. Misinterpretations of the nature of Aboriginal identities create a poor basis for formulating public policy. Early perspectives that discussed urban Aboriginal people only in terms of their cultural distinctness or only in terms of their socio-economic status, for example, led to inadequate policy initiatives that focused only on assimilation and upward mobility without acknowledging cultural distinction and the impacts of racism and colonial domination, or only on the recognition of cultural distinctness without addressing socio-economic issues (Culhane 2009). Better information about the nature of contemporary urban Aboriginal identities is an essential facet of understanding how contemporary cities with increasingly large Aboriginal populations work economically and socially. For governments, the research on urban Aboriginal identities provides insights into appropriate definitions of urban Aboriginal self-government, representation, and program definition; processes contributing to recent population increases; and factors that support or erode Aboriginal identities in cities.

In the rest of this article, I provide an overview of the state of our academic knowledge about urban Aboriginal identities in Canada. After a short explanation of the scope and methods for conducting this review, I describe some of the main themes that arise from the post-1996 literature. The first section is a description of colonial mechanisms of dispossession and displacement that defined cities as settlements where Aboriginal peoples and cultures were out of place before the focus moves on to the characteristics 
of contemporary cities that create challenges for the maintenance of urban Aboriginal cultures and identities. Next, I describe an emerging body of work that identifies the opportunities urban areas represent for the construction of positive Aboriginal identities, suggesting different ways Aboriginal and urban identities are related. Finally, by way of conclusion I describe some of the continuing gaps in this research.

\section{Scope and Methods}

With the exception of a few reports produced for the Royal Commission on Aboriginal Peoples, this article is a review of the literature on urban Aboriginal identities that have appeared subsequent to my own 1996 paper and the final report of the Royal Commission on Aboriginal Peoples. The focus is on the Canadian urban situation. While there is a growing literature on the characteristics of urban Aboriginal people (e.g., on their demographics, patterns of migration, socio-economic conditions, service needs, and organizations and self-government), the work I examine here has to do with urban Aboriginal identities and cultures. To ensure the work I review is accessible to readers, I have concentrated on published materials, but refer to several on-line theses that came to my attention. I did not systematically search for MA and PhD theses published since 1996. As a starting point, I perused papers in the Canadian Journal of Native Studies, The Native Studies Review, and the Journal of Aboriginal Economic Development, noting relevant papers and consulting bibliographies. I used key words in the ISI Web of Knowledge and in Google Scholar to search for additional references. I scrolled through the websites and papers of authors who have written on urban Aboriginal topics, and I canvassed the websites of government departments, especially the Office of the Federal Interlocutor for Métis and Non-Status Indians, Canadian Heritage, and Indian and Northern Affairs Canada. The possibility exists that articles relevant to the topic of urban Aboriginal identities in Canada could appear in many different disciplinary venues and government departments, which means that this review will inevitably have missed some papers. However the materials summarized here do address emerging themes that depart from earlier perspectives and provide an indication of some of the directions scholars in this area are taking. 


\section{Urban Implications of Colonialism}

A number of studies contribute to our understanding of the implications of colonialism for urban Aboriginal people's identities. One body of work elaborates on the mechanisms through which Aboriginal people were dispossessed of their lands in cities and displaced from urban space. Blomley $(2004,109)$ differentiates between the processes of dispossession and displacement. For him, dispossession refers to the changes in property ownership-Aboriginal people were disposed of urban lands through legal instruments, mapping, and surveying. Displacement refers to the removal of Aboriginal people from urban landscapes. Blomley argues that this process was comprised of two different elements: one was the conceptual removal of Aboriginal people from cities so that they were viewed as being out of place there, while the second element involved their material, or physical, removal and the emplacement of a settler society.

The conceptual removal of Aboriginal people from urban lands is not unique to Canada. As researchers have documented for other countries (Anderson and Domosh 2002; Berkhoffer 1979; Goldie 1989), Canadian cities were imagined as spaces of civilization in contrast to those of Indigenous savagery (Harris 2002; Lawrence 2004; Peters 2002; Wilson and Peters 2005). Blomley (2004, 117-18) identified colonial narratives of empty lands and expectations of inevitable assimilation that were components of this process. Other ways of enacting conceptual removal include urban histories that do not acknowledge prior Aboriginal occupation and a history of federal policy making that acknowledges responsibility only for on-reserve (i.e., primarily non-urban) residents (Peters 2001, 2004).

The relocation of reserves when cities grew around them, illegal surrenders of reserve lands near city boundaries, the pass system that confined First Nations people to reserves on the prairies, and the intense hostility many Aboriginal people faced when they visited urban areas all contributed to their physical removal from urban space (Blomley 2004; Sanger-Ross 2008; Wilson and Peters 2005). The marking of property (i.e., houses, fences, roads) helped to emplace settler society. Summarizing a growing body of literature on the historical processes of the displacement of urban Aboriginal people in Canada, Sanger-Ross (2008) identified the need to explore "municipal colonialism," and the role of city planning in erasing Aboriginal presences from the urban landscape in order to substitute a settler presence. He argued that municipal colonialism took distinct forms 
from federal and provincial colonialism and that municipal government strategy and attitudes varied from place to place (see also Edmonds 2004).

In the contemporary literature, there is also an emphasis on the implications of colonial institutions and experiences for ways many contemporary urban Aboriginal residents viewed themselves and the opportunities available to them (Frideres 2008). The Royal Commission $(1993,3)$ noted the "overwhelming problems that are rooted in cultural dislocation and powerlessness, discrimination and economic hardship" that faced many urban Aboriginal people. Berry's (1999) research for the Royal Commission, which involved learning circles from a variety of Aboriginal groups in six cities, found that influences on Aboriginal identity that participants considered as negative came primarily from the non-Aboriginal sphere, and included residential schools and government institutions. In interviews conducted by Silver et al. (2006, 10), Winnipeg inner-city Aboriginal community leaders indicated that residential schools, the educational, police and legal systems, and child and family services had shaped their lives, leading to loss of family and community, loss of identity and self-esteem, and lack of preparation for urban life. Two studies of urban Aboriginal gangs also implicated colonial histories (Deane et al. 2007; Grekul and LaBoucane-Benson 2008). According to Grekul and LaBoucane-Benson (2008,71), "A broader historical context marred by colonialism, discriminatory government practices and residential schools contributes to a situation where the label stigmatizes and propels the labeled further into a life of deviance; the label can in effect further deviant and criminal behavior."' Deanne et al. $(2007,136)$ noted that, in the context of negative stereotyping, many urban Aboriginal people struggled to hold positive views about themselves and their communities. Because of structural inequality, family, community and cultural breakdown, and systemic discrimination, gangs offered members an opportunity to feel a sense of self worth and identity.

While references to the ongoing colonial legacy are not absent in the pre-1996 literature on urban Aboriginal identities, the post-1996 literature insists more strongly that urban Aboriginal experiences need to be set into the context of that history. The conceptual and physical removal of Aboriginal peoples from urban spaces that accompanied colonization helped to reinforce perceptions about the incompatibility of urban and Aboriginal identities. The result was a nation divided into "primitive" spaces of Aboriginal culture and the "modern" space of urban Canadians, and these ideas continue to 
affect assumptions about urban Aboriginal identities in contemporary times. Stereotypes engendered by a variety of colonial institutions, processes that have been internalized, and socio-economic marginalization continue to affect the ways many urban Aboriginal people view their prospects and opportunities in the city. While it is important not to homogenize urban Aboriginal identities, it is also important to acknowledge the larger context of colonization that dispossessed them of their lands and languages, sent many children to residential schools, disrupted gender relations and patterns of governance, and impoverished reserves and rural Métis communities.

\section{Impact of City Populations and Characteristics}

Without losing an emphasis on the importance of the ongoing legacy of colonialism, contemporary work has also begun to identify how the characteristics of the city administration and populations, Aboriginal and non-Aboriginal, create challenges for the emergence and maintenance of positive urban Aboriginal identities. Four main threads in the literature include the effects of settler racism, the nature of municipal governance, the challenges of being surrounded by mainstream culture, and the heterogeneity of urban Aboriginal populations themselves.

\section{Settler Racism}

In its 1993 roundtable on urban issues, the Royal Commission (1993, 45) reported that "Aboriginal people face racial discrimination every day, in every urban centre, on the streets, at work, and sometimes at home." A number of studies documented how these attitudes create challenges for urban Aboriginal residents. In Absolon and Winchester's (1994, 359) learning circles with 114 Aboriginal participants in six cities, many indicated that the experience of racism on a daily basis led people to hide their identities from others and their children. Participants in Restoule's (2005) learning circles with urban Aboriginal men in Toronto indicated that, familiar with stereotypes of Aboriginal people, they frequently hid their identities and carefully monitored their behaviour and appearance to avoid the negative effects of racism. A theme in Lawrence's (2004) interviews with twenty-nine participants self-identifying as mixed-blood (Nativewhite) urban Natives was family denial of identity linked to racism in the settler community. In Winnipeg, twenty Aboriginal youth "opinion leaders" described racism as an impediment to positive identity development in the 
city (Belanger et al. 2003).

In her analysis of the court case concerning the 1995 murder of Pamela George, a Saulteaux woman in Regina, Razack $(2002$, 129) introduced the idea that inner-city spaces where many urban Aboriginal people are confined through poverty and discrimination are viewed by urban populations as places where "all that is not respectable is contained." The two white male university students charged with George's murder were convicted only of manslaughter. Based on her analysis of court transcripts, Razack argued that "In racialized space, violence may occur with impunity. Bodies from respectable spaces may also violate with impunity, particularly if the violence takes place in the racialized space of prostitution" (143). Assumptions about the nature of inner-city spaces, and therefore the rights of Aboriginal residents within them, exposed Aboriginal people to violence that appeared to be outside the justice system.

Devertuil and Wilson's 2010 evaluation of the existence of initiatives culturally appropriate for Aboriginal clients in Winnipeg healthcare treatment centres suggested that decision-making about models of health care in these institutions was based less on explicit racism and more on the ways in which non-Aboriginal cultures were naturalized, to the extent that practitioners were unaware of alternative approaches. They labelled urban areas as spaces of "white privilege," where non-Aboriginal practices are taken for granted and unexamined, excluding other cultural approaches to issues.

We argue that the indifference to Aboriginal specificity and the belittling of Aboriginal approaches to healing are more aligned to the concept of white privilege, where intent is less obvious, rather than to outright and demonstrable institutional racism within the treatment recovery system. In other words, there is no explicit denial of Aboriginal needs, but rather an indifference to them that speaks to the normalizing and embodied nature of white privilege. We thus find a situation where culture is potentially central to treatment but divorced in most services $(2010,505)$.

Whether non-Aboriginal society attitudes are viewed as settler racism or white privilege, the result denies urban Aboriginal identities full citizenship in urban areas. 


\title{
Contemporary municipal colonialism
}

Papers on contemporary municipal colonialism are closely related to research that employed racism and white privilege as organizing frameworks. Several papers documented ways that municipal practices failed to respect Aboriginal peoples' perceptions of their appropriate roles with respect to decision-making and service delivery in urban areas and ,as a result, denied Aboriginal identities as self-determining communities in urban areas. Newhouse and Peters (2003) argue that writing done about First Nations and Métis people in Canada most often associate the idea of community with rural and reserve settlements. In the city, First Nations and Métis populations are seen as heterogeneous, individual, and isolated. They note that, "The idea of Aboriginal community has been little explored in the literature. .. . Urban Aboriginal research has tended to focus upon the experiences of individuals and their adjustment to urban life, paying only incidental attention to community" (247). The implication is that urban Aboriginal communities have not been viewed as organized and capable of participation in decision-making about policies and programming. Walker (2006) documented differing perspectives on their roles in service delivery by Aboriginal and non-Aboriginal housing providers. He noted that,

\begin{abstract}
Aboriginal actors presented views on self-determination and Aboriginal control, cultural issues and differing needs and aspirations and the importance of their relationship with the federal government. Mainstream actors presented views on the merits of integrated programming and the perception of cultural neutrality in mainstream processes (470).
\end{abstract}

Walker concluded that Aboriginal definitions of their appropriate role in city government and administration were seen by municipal officials to be incompatible with the definition of mainstream urban citizenship (see also Wood 2003). Belanger and Walker (2009) argued that co-production of policies and programs between Aboriginal communities and municipal officials were required in order to recognize urban Aboriginal people's rights to self-determination. Examining Winnipeg's Aboriginal planning process, they argued that municipal leaders failed to engage with Aboriginal policy issues in ways that supported these rights. The failure to conceptualize Aboriginal identities differently from mainstream citizenship may form the basis for the lack of progress towards urban Aboriginal self-government 
documented in several recent papers (White and Bruhn 2010).

Challenges of being surrounded by non-Aboriginal people and cultures

The heterogeneity of cultures and peoples living in most urban areas means that Aboriginal community and cultural practices must be consciously sought out in cities. Frideres described the differences between living in an Aboriginal community and living in a city:

Aboriginal people have always had a cultural identity but in the past it was largely taken for granted since it was anchored to groups and roles and it was not a matter of choice. When people live in an Aboriginal community, work with other Aboriginal people and socialize with other Aboriginal people, there is little need to be concerned with cultural identity except during conflict with other ethnic groups or government (2008, 325-26).

In contrast, living as a minority population in an urban setting means the urban Aboriginal people are required to make conscious choices about defining and communicating their identities.

Similarly, in her interviews with twenty-nine participants selfidentifying as mixed-blood urban Natives, Lawrence $(2004,159)$ found that, in the absence of familiar markers of language, territory, and band government that characterized many Aboriginal communities, participants were required to expend considerable effort to express their Aboriginal identities: "The nature of urban life-where most work and home environments are organized in ways that ignore the demands of family or community, and where there are few all-Native spaces-encourages a growing individualism that only concerted struggle can challenge."

In its interviews with urban Aboriginal residents in Ontario, the Urban Aboriginal Task Force (2007) found that perceptions among Aboriginal people themselves created challenges for defining urban Aboriginal identities. Many participants felt that authentic Aboriginal identities were associated with tradition and living on the land, and as a result urban Aboriginal practices and identities were seen as not really Aboriginal. The Task Force $(2007,74)$ argued that:

[i]f alternative positive representations of being Aboriginal and new forms of Aboriginal cultural expressions along with 
institutions to support those expressions (such as cultural centres) are not available for this group to maintain their identity, they may feel marginalized and not participate in the Aboriginal community within the urban centre.

Patrick and Tomiak's $(2008,8)$ research on the Inuit in Ottawa came to a similar conclusion. Based on his work in the Canadian Arctic, Searlers (2010) noted that, despite increasing Inuit urbanization, authentic Inuit cultural identity is associated with being able to spend time on the land engaged in historic hunting and gathering activities. For the Inuit, urban spaces are seen as places where Inuit values and practices are eclipsed by non-Inuit people. These studies highlight the need to intentionally foster Aboriginal cultural identities in cities and the importance of Aboriginal spaces and institutions.

\section{Heterogeneity}

While urban Aboriginal people often appear in the media as uniformly marginalized, living in inner-city areas and with little recognition of unique cultural and legal histories, the reality is that urban Aboriginal peoples are characterized by considerable heterogeneity in their cultural and socioeconomic identities.

Clatworthy's (2000) study of the affiliations of First Nations people living in Winnipeg found a wide variety of band memberships and cultures represented in the urban population. Métis populations are similarly diverse, with different kinship affiliations and different sources of identity. Selfidentification in some cases associated with "mixed" Aboriginal and settler ancestry; in other cases, it derives from linkages with the historic Métis Nation of the Prairie provinces (Andersen 2008). Troupe (2009) argued that the historic role of familial ties among Métis women in organizing Métis communities continued to inform urban Métis community identities.

The cultural heterogeneity of urban Aboriginal residents calls for unique responses for urban Aboriginal residents. In its roundtable on urban issues, the Royal Commission on Aboriginal peoples $(1993,4)$ reported that: "The diversity of origins and cultures of Aboriginal people living in a particular city often poses difficulty in establishing a sense of community." Patrick and Tomiak $(2008,6)$ documented tensions between northern and southern-born Inuit "given that language and cultural skills and knowledge association with the North are the ones that clearly mark Inuitness." Proulx's 
(2003) study of Community Council Project (CCP), an alternative justice program designed for Aboriginal people in Toronto, provided an example of how this organization responded to issues of cultural heterogeneity. He indicated that, in the project, Anishnawbe cultural practices predominated but that there was also respect for other First Nations. Proulx (2003, 16364) argued that cultural inclusiveness was central to Aboriginal community in Toronto, but that there was continuing tension in the face of diversity and limited resources and "fears of the erosion of particular Aboriginal identities and practices, as programmatic pan-Aboriginal approaches appear poised to homogenize distinctiveness" (see also Frideres 2008). Pan-Aboriginal approaches may also be viewed as reflecting colonial perspectives that did not differentiate between unique Aboriginal cultures.

Individuals in urban areas appear to employ a variety of strategies to cope with particular and more inclusive urban Aboriginal practices. Wilson and Peters (2005) found that, because they were in a minority and events were infrequently organized following only Anishnabe protocols, urban Anishnabe people living in Toronto participated in ceremonies governed by other First Nations customs and practices. When they wished to experience their own language and ceremonies, they often traveled to their home reserve. Proulx $(2006,421)$ argued that some urban Aboriginal peoples utilized culturally specific and pan-Aboriginal resources strategically "during policy and program negotiations with non-Aboriginal stakeholders," suggesting that these options were not mutually exclusive.

Variations in class identities also characterize urban Aboriginal populations. Urban Aboriginal people with low socio-economic status are frequently featured in the media and in policy research. LaPrairie (2003) argued that Aboriginal over-representation in the criminal justice system was strongly related to urban Aboriginal marginalization. Against public perceptions that homogenize urban Aboriginal populations as uniformly socio-economically disadvantaged and concentrated in inner-city ghettos, Peters (2010) pointed out that there is a growing middle class in the urban Aboriginal community, and demonstrated that Aboriginal people are relatively dispersed in urban areas compared to other minority populations both in Canada and in US cities. She argued that the homogenization of Aboriginal identities and assumptions that they were bounded in innercity space limited the appropriateness and effectiveness of policies and programs available to urban Aboriginal residents. While there has been little follow-up analysis, Wotherspoon's (2003) work with 1996 census 
data suggested that there was an emerging middle class amongst urban Aboriginal populations. He $(2003,155)$ noted that in urban areas "many public and private sector agencies in both Aboriginal and non-Aboriginal sectors have created initiatives, programs, and hiring policies to attract highly qualified Aboriginal candidates." According to Wotherspoon (2003, 156), this replicated the way the non-Aboriginal middle class emerged historically. Focus groups with Aboriginal middle-class Toronto residents highlighted the importance of recognizing the socio-economic diversity of urban Aboriginal people (Urban Aboriginal Strategy 2005). The Toronto study indicated that middle-class urban Aboriginal people did not access Aboriginal organizations because these organizations are mostly service organizations focusing on a variety of social problems. Instead, they emphasized the need for Aboriginal language and cultural programs that addressed their aspirations.

Lawrence's (2004) interviews with individuals self-identifying as mixed blood (Aboriginal and non-Aboriginal) in Toronto highlighted an interesting implication of urban life for the diversity of Aboriginal identities. She noted that the opportunities that cities presented for relationships between Aboriginal and non-Aboriginal people meant that urban Aboriginal communities had a growing proportion of individuals who might choose to identify as either Aboriginal or non-Aboriginal. For Lawrence's participants, Aboriginal and non-Aboriginal ancestry often led to confusion over identity. However the analysis by Guimond et al. (2009) of Aboriginal population growth in recent censuses suggested that the self-identification of individuals with Aboriginal and non-Aboriginal parents as Aboriginal represented a significant source of recent population growth for urban Aboriginal populations. The processes through which individuals choose Aboriginal identities under these circumstances were not well explored.

While some research has focused on gender, socio-economic status in the city, and migration (see, e.g., Jaccoud and Brassard 2003), there is relatively little work that explores gendered Aboriginal identities in the urban milieu. The work that does exist suggests that it is important to take gendered identities into account in urban Aboriginal policy making. To date, the focus of gender analysis in this body of research has been on Aboriginal women. Research by Benoit et al. (2003) with Aboriginal women on Vancouver's East Side, for example, found that participants felt there was a need for health services that addressed gender as well as culture and marginalization. Peters' (1998) analysis of transcripts of presentations to the Royal 
Commission on Aboriginal Peoples by Aboriginal women living in cities showed that their perceptions of self-government were based on kinship ties rather than hierarchical relationships and, as a result, women rejected the usefulness of models of self-government that distinguished between urban and non-urban communities. Several case studies document the leadership roles Aboriginal women take in creating networks and organizations to support urban Aboriginal communities, resisting stereotypes about the inappropriateness and ineffectiveness or Aboriginal cultural frameworks in urban areas (Howard-Bobiwash 2003; Janovicek 2003; Silver 2006). Other papers focused on the implications of extreme marginalization and stereotyping for Aboriginal women's lives in urban areas. Culhane (2003) documented ways that Aboriginal women in Vancouver's downtown East Side resisted stereotypes that labeled them solely as prostitutes, drug addicts, and welfare cheats through the annual Valentine's Day Women's Memorial March. Instead, they emphasize their roles as "givers of life, mothers, sisters, daughters, aunties and grandmothers" (593).

Acknowledging the diversity of urban Aboriginal communities is an important basis for public policy. Failure to recognize the diversity of cultures and legal status creates pressure for homogenization that may alienate some urban residents. Assumptions about uniform marginality and targeting of interventions primarily in inner-city areas ignores the needs of other Aboriginal populations and may contribute to increased segregation and stigmatization. Urban Aboriginal identities are also cross-cut by other dimensions, such as age and generation, sexuality, and ability, but these aspects have received almost no attention in the literature.

\section{Urban Opportunities for the Existence of Positive Aboriginal Identities}

While researchers have begun to identify the challenges that cities present for the maintenance, revitalization, or emergence of positive urban Aboriginal identities, there is also work that describes cities as place of opportunity for Aboriginal identity construction. While the themes in this work are not fully developed, four main perspectives on the relationship between Aboriginal identities and urban life thread through these materials. While some of these perspectives may appear to contradict each other, it is also possible that different situations are characteristics of different segments of the urban Aboriginal community. 
One theme denies the usefulness of the separate category "urban Aboriginal" in referring to the nature of Aboriginal cultural identities. Levesque's (2003) piece, for example, could be placed in this category. Based on the Quebec case, she argued that with the development of an Aboriginal civil service and the location of Aboriginal organizations in urban areas servicing reserves and rural communities, the Aboriginal sphere has expanded to include urban areas, so that both cities and rural communities are part of ordinary Aboriginal ways of life and identity. Urban and non-urban people are part of the same Aboriginal community, and cities and reserves are connected as individuals circulate between them A similar argument appears in Darnell and Munguia's (2005) research on the movements of Algonquian and Iroquoian peoples back and forth between the city of London, Ontario and local reserves. They wrote:

The study deconstructs the rigid image of the "the urban Indian" which is too often taken for granted in the social science literature. There is considerable need to document, particularly for demographers, the flexibility with which actual people move around a territory that encompasses both urban and rural settlements, not randomly but in search of exploitable resources ... Indeed, the categories of urban and rural/reserve Indian may be highly misleading in reflecting the experiences and decisionmaking of our consultants as expressed in their life history narratives $(2005,173,185-86)$.

A second theme in this literature challenges perceptions about the incompatibility of Aboriginal culture and urban life, emphasizing that it is possible to build positive Aboriginal identities in cities. A major emphasis in this literature is to identify elements that support the expression of urban Aboriginal identities. Silver et al. $(2006,26)$ found in their interviews with twenty-six Winnipeg inner-city Aboriginal community leaders that adult education for Aboriginal people, Aboriginal organizations based on Aboriginal culture, and parenting and involvement in schools contributed to rebuilding "the pride in being Aboriginal and an understanding of the process and consequences of colonization." Le Clair et al. (2003) documented the process through which an urban Métis women's group came together to relearn their culture and identity from each other and through research and through contact with elders. Important contributors to the support of 
urban Aboriginal identities as listed by respondents in the Ontario Urban Aboriginal Task Force (2007) were: being with other members of the urban Aboriginal community; the values of caring, family, food, and daily acts of sharing; traditional teachings, ceremonies and elders; languages; and cultural events. The twenty Winnipeg Aboriginal youth interviewed by Belanger et al. (2003) indicated that important sources of Aboriginal cultural identities in urban areas were their grandparents, Aboriginal programming in the city, and the media. They associated Aboriginal cultural identities with traditional activities (i.e., smudging, dancing, and powwows) and events that aid in identity construction in the urban setting, such as university courses and programs for Aboriginal youth.

In a third theme, writers agree that Aboriginal cultures and identities and the urban milieu are not incompatible, but view them as dynamically constructed in response to the challenges and opportunities of urban life. For researchers proposing this line of argument, the category of "urban Aboriginal" is meaningful. Urban Aboriginal identities are not simply transferred from earlier traditions or from remote Aboriginal communities. They draw instead on cultural traditions and identities, but these are consciously and systemically being reconstructed differently in cities. David Newhouse's work is probably most clearly associated with this approach in Canada. He $(2000,404)$ argued that the experience of being Aboriginal may be different for an increasingly urban-based Aboriginal population than for earlier, more rural peoples, and urban Aboriginal people may not live close to the land and they may not live lives like their ancestors. In this situation, Aboriginal culture may become heritage rather than a way of life. In order to survive in the city, "[i]t does mean that one will need to take extraordinary steps to ensure the survival of Aboriginal cultures, including languages and spirituality." Newhouse $(2000,406)$ noted that, in the city,

Aboriginal identity is being examined on both an individual and collective basis, and it is being deliberately reconstructed by Aboriginal institutions, educators, communities and band leaders to be as Aboriginal as possible. This examination has made Aboriginal societies think carefully about their assumptions, values and ways of doing things.

For Newhouse $(2003,251)$, the existence of urban Aboriginal organizations is key in this process as they reflect the "presence of urban Aboriginal 
people who are interested in creating and participating in healthy vibrant communities and who see the city as an opportunity and renewal rather than a place of cultural erosion."

Some of the papers reviewed for this study lend support for this third perspective. The Urban Aboriginal Task Force $(2007,74)$ noted the importance of building "alternative positive representations of being Aboriginal and new forms of Aboriginal cultural expressions" in urban areas. Proulx (2003) characterized the Toronto Community Council Project (CCP), an alternative justice program designed for Aboriginal people in Toronto, as being "based on revitalized Anishnawbe traditions and spirituality updated to deal with the new contingencies of urban life." Proulx's (2006) identification of the tensions around identity experiences by individuals who knew they were Aboriginal but who had no ties to reserve or other sources of Aboriginal culture demonstrated the importance of a perspective the views urban Aboriginal cultures as emergent. He wrote that:

Aboriginal peoples who are not connected to culturally specific identity relations must use whatever resources at their disposal to create or claim Aboriginal identities thereby filling the holes in their hearts. How individuals choose to identify and the resources they chose to use in this process must be understood as flexibly inventive reacting to both internal and external personal and cultural change $(2006,423)$.

Deane et al. (2004) highlighted a similar theme in their research in a Winnipeg neighbourhood, where they attempted to explore why Aboriginal community members were not connected to variety of mainstream organizations attempting economic development. In their interviews, they found that Aboriginal residents considered mainstream organizations to practice values based on charity, which created indignity for Aboriginal residents. Alternative Aboriginal values of reciprocity and giving back led Aboriginal residents to rely, instead, on their own social networks. Deane et al $(2004,242,246)$ argued that:

$[\mathrm{M}]$ any urban Aboriginal people have value orientations that differ significantly from the mainstream, and . . . these norms exert significant influence on individual action and behaviour. . . . Aboriginal culture may be a collage of jigsaw puzzle fragments, it 
may be an amalgam of traditional values, mainstream adaptations, and inner city survival skills, but urban Aboriginal culture is nevertheless recognizable to those who share it, and powerful in its normative influence. There is a strong quest on the part of inner city Aboriginal people for cultural coherence, personal identity, and community completeness.

Finally, the idea that cultural revitalization originates in cities is not very well developed in the Canadian context (see, e.g., Ramirez 2007 for contrast), but this theme was supported in two of the pieces reviewed for this paper. Warry $(2007,111)$ stated that "Urban Aboriginal peoples and the choice they make, are central to cultural revitalization. Indeed, the Aboriginal cultural revitalization movement was born in the city and not on reserve." Interviews made by Belanger et al. (2003) with twenty Aboriginal youth in Winnipeg found that they viewed reserves negatively, characterizing them as places where "alcoholism was normal and violence the norm." The youth perceived a lack of Aboriginal identity on reserves and indicated that their own sense of identity was facilitated by social programming in the city. In contrast with well-worn stereotypes that perceive "authentic" Aboriginal cultures as static formations with locales far removed from urban life, this approach views Aboriginal cultures as dynamic but emerging from urban life, rather than within rural communities.

While different interpretations of the relationship between urban life and Aboriginal identities exist, they all emphasize that life in an urban setting is not incompatible with the maintenance or emergence of vibrant and varied Aboriginal identities. These argument appear to be reflected in recent demographic processes, which show a rapid growth in urban Aboriginal populations that cannot be explained only by demographic factors such as fertility, mortality, and migration (Guimond 2003). Legislation allowing for the reinstatement of First Nations people who had lost their legal status as Registered Indians accounted for part of the increase in recent decades, because many individuals who lost their status were living in urban areas. However, much of the population increase came about because individuals who did not identify as Aboriginal in previous census years were now choosing to do so. Most of the increase associated with changes in selfidentification has occurred in urban areas (Guimond et al. 2009, 16), with the largest proportionate increase among Métis people. Siggner (2003) suggested that changing attitudes toward Aboriginal peoples in Canada 
were important in changing patterns of self-identification. Researchers have documented a similar phenomenon in the US, identifying US ethnic polities that embrace ethnic pride and Indian activism as contributing factors (Nagel 1995).

\section{Conclusion and Suggestions for Further Research}

Research on urban Aboriginal identities in Canada has come a long way since 1996. There is a substantial body of work addressing a variety of issues from many disciplinary perspectives, and there have been some major shifts in emphasis. Increasingly, there is work that examines the mechanisms through which cities are defined so that Aboriginal cultures and identities are viewed as being out of place in them. There are strong arguments that success in the urban milieu is not incompatible with the retention or emergence of positive Aboriginal identities and communities. Especially encouraging is the increasing number of Aboriginal researchers addressing urban Aboriginal issues.

While these changes are encouraging, gaps and tensions remain in the existing work that would benefit from additional research. First, much of the existing work emphasizes description and does not develop a strong theoretical analysis. While the descriptive material is useful in providing a sense of the nuances and details of particular issues, it would also be useful for researchers to use these cases to evaluate the extent to which the experiences of urban Aboriginal people are similar to or dissimilar from other cultural groups in urban areas. This is not to say that Aboriginal people are like immigrant or other urban cultural groups, but it is important to begin to theorize how and why they are the same or different. Frameworks from Western sources should not be the only source of theoretical conceptsresearchers should engage with perspectives from Aboriginal ways of knowing as well. A US example of work that attempts to employ Aboriginal frameworks of meaning to frame identities is Eva Garroutte's 2003 book, Real Indians: Identity and the Survival of Native America.

The diversity of urban Aboriginal populations is under-researched. For example, much of the existing work either homogenizes Aboriginal urban experiences or focuses on the situation of First Nations people. Work on urban Métis and Inuit is under-represented. There are important cultural differences between different Aboriginal peoples, and they have experienced different histories. Similarly, Aboriginal people of different age groups and 
migration status vary in the ways that they develop and express their urban identities, and this has not received attention in the Canadian context. Finally, there is almost no work that explores developments in particular cities. At present, work focusing on Winnipeg represents the most substantive body of research in this area, but comparative work that explores how particular urban histories and characteristics shape Aboriginal identities in different cities would make a solid contribution to our knowledge. Attention to similarities and differences between peoples and cities would help to create a more robust scholarship in this area.

Research on urban Aboriginal identities is central to the development of public policies for urban Aboriginal people and for the non-Aboriginal people with whom they are neighbours. Recent research on urban Aboriginal policy making in different cities in Canada demonstrates varied understanding of the issues and, in many cases, complete obliviousness to their importance (Hanselmann 2001; 2002a; 2002b). In the absence of research on these issues, policy making for urban Aboriginal people makes assumptions about what these identities are, often drawing on theoretical frameworks designed to explain the experiences of other groups (e.g., immigrants or US black inner-city residents) or on long-standing stereotypes. Further development in this research would contribute not only to a better understanding of the unique nature of urban Aboriginal identities - it would also improve our understanding of Canadian cities and the ways in which different people live in them. While research in this area has come a long way in the last decade and a half, there is still a long way to go.

\section{(Endnotes)}

1. Following the Constitution Act (1982 as amended), I use the term "Aboriginal peoples" to refer to the Indian, Métis, and Inuit peoples of Canada. Most contemporary writers use "First Nations" instead of "Indian." When discussing official government policies, I adopt the terms used in colonial and Canadian government policies and statistics (e.g., Registered Indian, Native, etc.). When referring to a specific First Nations community, I use particular names such as Mi'kmaq, Cree, or Ojibway. I also recognize that the term Métis has different and contested meanings; sometimes it refers to descendants of First Nations and European people, and sometime 
it refers to the Métis Nation that emerged in the Prairie provinces. Finally, I recognize that the term "Inuit" similarly aggregates different peoples.

2. LaPrairie (2002) disputes this as an explanatory framework, noting the diversity of incarceration rates in different cities as well as the links between socio-economic marginalization and involvement with the criminal justice system. Particular histories and the linkages between colonial impacts and contemporary conditions of urban Aboriginal people need much more research.

\section{References}

Absolon, Kathleen E. and R. Anthony Winchester. 1994. Cultural Identity for Urban Aboriginal Peoples: Learning Circles Synthesis Report. Draft. Ottawa: Royal Commission on Aboriginal Peoples, Urban Perspectives.

Andersen, Chris. 2008. "From Nation to Population: The Racialisation of 'Métis' in the Canadian Census." Nations and Nationalism 14 (2): 347-68.

Andersen, Chris and Claude Denis. 2003. "Urban Native Communities and the Nation Model: Before and After the Royal Commission on Aboriginal Peoples." Canadian Review of Sociology and Anthropology 40 (4): 373-390.

Anderson, Kay and Mona Domosh. 2002. "North American Spaces/ Postcolonial Stories." Cultural Geographies 9 (2): 125-28.

Belanger, Yale and Ryan C. Walker. 2009. "Interest Convergence and CoProduction of Plans: An Examination of Winnipeg's Aboriginal Pathways.” Canadian Journal of Urban Research 18 (1): 118-39

Belanger, Yale, Liz Barron, Charlene McKay-Turnbull, Melanie Mills. 2003. Urban Aboriginal Youth in Winnipeg: Culture and Identity Formation in Cities. Report prepared for Canadian Heritage, Winnipeg, MB. 
Benoit, Cecelia, Dena Carroll, and Munaza Chaudhry. 2003. "In Search of a Healing Place: Aboriginal women in Vancouver's Downtown Eastside." Social Science and Medicine 56 (6): 821-33.

Berkhoffer, Robert. 1979. The White Man's Indian: Images of the American Indian from Columbus to the Present. New York: Vintage Press.

Berry, John W. 1999. “Aboriginal Cultural Identity.” Canadian Journal of Native Studies 19 (1): 1-36.

Blomley, Nicholas. 2004. Unsettling the City: Urban Land and the Politics of Property. New York; London: Routledge.

Cairns, Allen C. 2000. Citizens Plus: Aboriginal Peoples and the Canadian State. Vancouver: UBC Press.

Clatworthy, Stewart. 2000. First Nation Affiliation Among Registered Indians Residing in Select Urban Areas. Ottawa: Minister of Public Works and Government Services Canada.

Culhane, Dara. 2009. "Narratives of Hope and Despair in Downtown Eastside Vancouver." In Healing Traditions: The Mental Health of Aboriginal Peoples in Canada, ed. Laurence J. Kirmayer and Gail G. Valaskakis, 160-177. Vancouver: UBC Press.

Culhane, Dara. 2003. "Their Spirits Live within Us: Aboriginal Women in Downtown Eastside Vancouver Emerging Into Visibility." American Indian Quarterly 27 (3-4): 593-606.

Darnell, Regna, and Maria Cristina Manzano Munguia. 2005. "Nomadic Legacies an Urban Algonquin Residence." In Papers of the ThirtySixth Algonquian Conference, ed. H.C. Wolfart, 173-86. Winnipeg, MB: University of Manitoba.

Deane, Lawrence, Denis C. Bracken, and Larry Morrissette. 2007. "Desistance Within an Urban Aboriginal Gang." The Journal of Community and Criminal Justice 54 (2): 125-41. 
Deane, Lawrence, Larry Morrissette, Jason Bousquet, and Samantha Bruyere. 2004. "Explorations in Urban Aboriginal Neighbourhood Development." The Canadian Journal of Native Studies XXIV (2): 227-52.

DeVerteuil, Geoffrey, and Kathi Wilson. 2010. "Reconciling Indigenous Need with the Urban Welfare State? Evidence of Culturally Appropriate Services and Spaces for Aboriginals in Winnipeg, Canada." Geoforum 41 (3): 498-507.

Edmonds, Penelope. 2004. "From Bedlam to Incorporation: Whiteness and the Racialization of Colonial Urban Space in Victoria, British Columbia and Melbourne, Victoria, 1840s-1880s." In Exploring the British World: Identity, Cultural Production, Institutions, ed. Kate Darian-Smith, et al, 60-90. Melbourne, AU: RMIT.

Frideres, James. 2008. "Aboriginal Identity in the Canadian Context." The Canadian Journal of Native Studies XXVIII (2): 313-42.

Flynn, Lindy-Lou. 1995. "Buffalo Burgers With Cappuccino: Urban Indians In Vancouver." In "North American Indians: Cultures in Motion," ed. Elvira Stefania Tiberini, special edition, L'Uomo. Societa Tradizione Sviluppo, Universita di Roma "La Sapienza." Vol. VII n.s.n.1: 45-62.

Garroutte, Eva M. 2003. Real Indians: Identity and the Survival of Native America. Berkeley and Los Angeles: University of California Press.

Goldie, Terry. 1989 Fear and Temptation: The Image of the Indigene in Canadian, Australian, and New Zealand Literatures. Montreal and Kingston: McGill-Queen's University Press.

Grekul, Jana and Patti LaBoucan-Benson. 2008. “Aboriginal Gangs and Their (Dis)placement: Contextualizing Recruitment, Membership, and Status." Canadian Journal of Criminology and Criminal Justice 50 (1):58-92. 
Guimond, Eric, Norbert Robitaille and Sacha Senécal. 2009. “Aboriginal Populations in Canadian Cities: Why Are They Growing So Fast?" Canadian Issues (Winter): 11-17.

Guimond, Eric. 2003. "Fuzzy Definitions and Population Explosion: Changing Identities of Aboriginal Groups in Canada." In Not Strangers in These Parts. Urban Aboriginal Peoples,, ed. David Newhouse and Evelyn J. Peters, 35-50. Ottawa: Policy Research Initiative.

Hanselmann, Calvin. 2001. Urban Aboriginal People in Western Canada. Calgary, AB: Canada West Foundation.

- - - 2002a. Uncommon Sense: Promising Practices in Urban Aboriginal Policy-Making and Programming. Calgary, AB: Canada West Foundation.

- - - 2002b. Enhanced Urban Aboriginal Programming in Western Canada. Calgary, AB: Canada West Foundation.

Harris, Cole. 2002. Making Native Space: Colonialism, Resistance, and Reserves in British Columbia. Vancouver: UBC Press.

Howard-Bobiwash, Heather. 2003. "Women's Class Strategies as Activism in Native Community Building in Toronto." American Indian Quarterly 27 (3-4): 566-82.

Jaccoud, Mylène and Renée Brassard. 2003. "The Marginalization of Aboriginal Women in Montréal." In Not Strangers in These Parts. Urban Aboriginal Peoples, ed. David Newhouse and Evelyn J. Peters, 131-45. Ottawa: Policy Research Initiative.

Janovicek, Nancy. 2003. “'Assisting our own': Urban Migration, SelfGovernance , and Native Women's Organizing in Thunder Bay, Ontario, 1972-1989." American Indian Quarterly 27 (3-4): 548-65.

Lawrence, Bonita. 2004. "Real" Indians and Others: Mixed-Blood Urban Native Peoples and Indigenous Nationhood. Lincoln: University of Nebraska Press. 
LeClair, Carole and Lynn Nicolson, with Métis Elder Elize Hartley. 2003. From the Stories that Women Tell: The Métis Women's Circle. In Strong Women Stories: Native Vision and Community Survival, ed. Kim Anderson and Bonita Lawrence, 38-54. Toronto: Sumach Press.

LaPrairie, Carol. 1995. "Seen But Not Heard: Native People in Four Canadian Inner Cities. Critical Criminology 6 (2): 30-45.

- - - 2002. "Aboriginal Over-Representation in the Criminal Justice System: A Tale of Nine Cities" Canadian Journal of Criminology 44: 181-208.

- - - 2003. "Aboriginal Over-Representation in the Criminal Justice System." In Not Strangers in These Parts: Urban Aboriginal Peoples, ed. David Newhouse and Evelyn J. Peters, 179-94. Ottawa: Policy Research Initiative.

Levesque, Carol. 2003. "The presence of Aboriginal Peoples in Quebec's Cities: Multiple Movements, Diverse Issues." In Not Strangers in These Parts: Urban Aboriginal Peoples, ed. David Newhouse and Evelyn J. Peters, 23-34. Ottawa: Policy Research Initiative. Nagel, Joan. 1995. "American Indian Ethnic Renewal: Politics and the Resurgence of Identity.” American Sociological Review 60: 947-65.

Newhouse, David. 2003. “The Invisible Infrastructure: Urban Aboriginal Institutions and Organizations." In Not Strangers in These Parts: Urban Aboriginal Peoples, Newhouse, ed. David Newhouse and Evelyn J. Peters, 243-54. Ottawa: Policy Research Initiative.

Newhouse, David. 2000. "From the Tribal to the Modern: The Development of Modern Aboriginal Societies." In Expression in Canadian Native Studes, ed. Ron F. Laliberte, et al. Saskatoon: University of Saskatchewan Extension Press.

Newhouse, David and Evelyn J. Peters. 2003. Not Strangers in These Parts: Urban Aboriginal Peoples. Ottawa: Policy Research Initiative. 
Patrick, Donna and Julie-Ann Tomiak. 2008. "Language, Culture and Community among Urban Inuit in Ottawa." Études/Inuit/Studies 32 (1): 55-72.

Peters, Evelyn J. 1996. “Aboriginal People in Urban Areas.” In Visions of the Heart: Canadian Aboriginal Issues, ed. David Long and Olive P. Dickason, 305-34. Toronto: Harcourt Brac.

- - . 1997. "Challenging the Geographies of 'Indianess': The Batchewana Case.” Urban Geography 18 (1): 56-62.

- - . 1998. "Subversive Spaces: First Nations Women and the City in Canada." Society and Space 16 (6): 665-86.

- - - 2001. "The Geographies of Aboriginal Populations and Rights in Canada." The Canadian Geographer 45 (1): 138-44.

- - - 2002 “"Our City Indians': Negotiating the meaning of First Nations urbanization in Canada, 1945-1975." Journal of Historical Geography 30: 75-92.

- - - .2004. "Conceptually Unclad? Feminist Geography and Aboriginal Peoples." The Canadian Geographer 48 (3): 1-15.

- - - 2005. "Indigeneity and Marginalization: Planning For and With Urban Aboriginal Communities in Canada." Progress in Planning 63 (4): 327-404.

- - - 2010. “Aboriginal People in Canadian Cities." In Canadian Cities in Transition: New Directions in the Twenty-First Century. 4th ed., ed. Trudi Bunting, Pierre Filion, and Ryan Walker, 375-390. Don Mills, ON: Oxford University Press.

Proulx, Craig, 2003. Reclaiming Aboriginal Justice, Identity and Community. Saskatoon: Purich Publishing.

- - . 2006. "Aboriginal Identification in North American Cities." Canadian Journal of Native Studies 26 (2): 405-39. 
Ramirez, Renya K. 2007. Native Hubs: Culture, Community and Belonging in Silicon Valley and Beyond. Durham, NC: Duke University Press.

Razack, Sherene, H. 2002. "Gendered Racial violence and Spatialized Justice: The Murder of Pamela George." In Race, Space and the Law: Unmapping a White Settler Society, ed. Sherene H. Razack, 131-56. Toronto, ON: Between the Lines.

Restoule, Jean-Paul. 2005. Male Aboriginal Identity Formation in Urban Areas: A Focus on Process and Context. PhD diss, Ontario Institute for Studies in Education (OISE), University of Toronto.

Royal Commission on Aboriginal Peoples. 1993. Aboriginal Peoples in Urban Centres. Report of the National Round Table on Aboriginal Urban Issues. Ottawa: Minister of Supply and Services Canada.

Searles, Edmond. 2010. "Placing Identity: Town, Land, and Authenticity in Nunavut, Canada." Acta Borealia 27 (2): 151-66.

Siggner, Andrew. 2003. "The Challenge of Measuring the Demographic and Socio-Economic Condition of the Urban Aboriginal Population." In Not Strangers in These Parts: Urban Aboriginal Peoples, ed. David Newhouse and Evelyn Peters, 119-39. Ottawa: Policy Research Initiative.

Silver, Jim. 2006. In Their Own Voices: Building Urban Aboriginal Communities. Halifax: Fernwood.

Sanger-Ross, Jordan. 2008. "Municipal Colonialism in Vancouver: City Planning and the Conflict over Indian Reserves, 1928-1950s." The Canadian Historical Review. 89 (4): 543-80.

Troupe, Cheryl L. 2009. Métis Women: Social Structure, Urbanization and Political Activism, 1850-1980. MA thesis, University of Saskatchewan.

Urban Aboriginal Strategy. 2005. Urban Aboriginal Task Force Progress 
Report 1._http://www.servicecanada.gc.ca/eng/on/epb/uas/reports/ uatfphase 1. shtml\#intro.

Urban Aboriginal Task Force. 2007. Urban Aboriginal Task Force. Final Report. Toronto, ON: Ontario Federation of Indian Friendship Centres.

Walker, Ryan C. 2006. "Interweaving AboriginaИndigenous Rights with Urban Citizenship: A View from the Winnipeg Low-Cost Housing Sector." Citizenship Studies 10 (4): 391-411.

Warry, Wayne. 2007. Ending Denial: Understanding Aboriginal Issues. Peterborough, ON: Broadview Press.

White, Jerry P. and Jodi Bruhn, eds. 2010. Aboriginal Policy Research: Exploring the Urban Landscape. Toronto, ON: Thompson Educational Publishing.

Wilson, Kathie and Evelyn J. Peters. 2005. “'You can make a place for it.' Remapping Urban Remapping Urban First Nations Spaces of Identity." Society and Space, 23: 395-413.

Wood, Patricia,K. 2003.“'A Road Runs Through It:'Aboriginal Citizenship at the Edge of Urban Development." Citizenship Studies 7 (4): 46379.

Wotherspoon, Terry. 2003. "Prospects for a New Middle Class Among Urban Aboriginal People." In Not Strangers in These Parts. Urban Aboriginal Peoples, ed. David Newhouse and Evelyn J. Peters, 147-66. Ottawa: Policy Research Initiative. 